\title{
Enhancing the Efficiency of Removing Support Material from Rapid Prototype Parts using pH Value Compensation Technology
}

\author{
Chil-Chyuan KUO ${ }^{1 *}$, Chun-Chieh HUNG ${ }^{1}$ \\ ${ }^{1}$ Department of Mechanical Engineering, Ming Chi University of Technology No. 84, \\ Gungjuan Road, New Taipei City 243, Taiwan \\ crossref http://dx.doi.org/10.5755/j01.mm.21.2.6523
}

Received 23 February 2014; accepted 17 May 2014

\begin{abstract}
Removing support material from rapid prototyping (RP) parts fabricated by fused deposition modeling (FDM) is required. Removing the support material rapidly and efficiently is an important concern because the product life cycle is shorter than before. The measurement of $\mathrm{pH}$ value in solution is an important issue affecting the efficiency of removing support material. In this work, a method was proposed to enhance the efficiency of removing support material from rapid prototype parts using $\mathrm{pH}$ value compensation technology. It is found that the $\mathrm{pH}$ value 11.6 is a good candidate for compensating the solution during removing process. The efficiency of removing support material increases with increasing the times of compensation. The savings in the removing time is up to $72 \%$ using $\mathrm{pH}$ value compensation technology.

Keywords: support material, fused deposition modelling, solution, $\mathrm{pH}$, compensation.
\end{abstract}

\section{INTRODUCTION}

New market realities need faster product development due to global competition. To effectively shorten new product development time, rapid prototyping (RP) was developed [1,2]. RP is a manufacturing technology that fabricates three-dimensional (3D) physical models using the layer by layer building process that stacks and bonds thin layers in one direction. Prototyping is an essential part of the product development and manufacturing cycle required for accessing the form of a design before conventional steel tooling is made. In comparison with the numerically controlled manufacturing technology, RP can rapidly manufacture physical models with complex shapes without geometric restriction under more comfortable working environments. Fused deposition modelling (FDM) is one method among a few capable of developing rapid prototyping parts from a thermoplastic material such as polycarbonate, acrylonitrile butadiene styrene (ABS), investment casting wax, and medical grade ABS. FDM is one of the most promising RP techniques in terms of dimensional accuracy, speed and cost-effectiveness. This system is viewed as a desktop prototyping facility in an office because the materials it uses are non-toxic and nonsmelly. Physical models made by this system have a high stability because they are not hygroscopic. A commercial FDM machine uses a computer numeric controlled extruderhead which squeezes a fine filament of melted thermoplastic through a nozzle. The controller activates the nozzle to deposit heated plastic layer-by-layer to build the desired 3D physical models. In general, FDM machine possesses a second nozzle for fabricating the structures to support any overhanging section of the prototype. In recent years, some issues about FDM technology have been intensively studied by many researchers all over the world. These issues include improving the surface finish of fused deposition modeled

\footnotetext{
*Corresponding author. Tel. : +886-2-29089899 ext. 4524; fax.: +886-2-
} 29063269. E-mail address: jacksonk@mail.mcut.edu.tw (Ch.-Ch. Kuo) parts [3], improving dimensional accuracy of fused deposition modeled parts [4], development of new materials for FDM system [5], development of a mobile FDM system [6], fabrication of scaffolds using FDM system [7] and fabrication of medical implants using FDM system [8]. In practice, support material of the RP part should be removed when the physical model is further employed. Thus, removing the support material from the RP part produced from the FDM-based machine efficiently is an important concern because the product life cycle is shorter than before. The major process parameters influencing the removal efficiency of support material were investigated in previous works $[9,10]$, showing the $\mathrm{pH}$ value of the solution is a major factor affecting the efficiency of removing support material from rapid prototype parts. The efficiency of removing support material is significantly reduced when the $\mathrm{pH}$ value of the solution is lower than 11 . Thus, monitoring the $\mathrm{pH}$ value of solution and compensate the $\mathrm{pH}$ value changed are critical to the efficiency of removing support material during removing process. In this work, a new method was proposed to enhance the efficiency of removing support material from rapid prototype parts using $\mathrm{pH}$ value compensation. Effects of compensation point of $\mathrm{pH}$ value of solution and times of compensation on the removal efficiency of support materials were investigated experimentally. Some good results have been obtained and discussed. The saving in the removing time using $\mathrm{pH}$ value compensation was also investigated and discussed. Plastic materials are widely used in 3C products, optical elements, and electronic goods, automotive and packaging. It is well known that plastic injection molding is one of the most important polymer manufacturing processes in plastic industry because it can produce complex-geometry plastic parts with good dimensional accuracy under very short cycle time. In this study, a simple and cost-effective approach for fabricating a precision epoxy resin mold using rapid tooling technology was proposed. The Taguchi design method is an efficient and effective experimental approach that can reduce the experimental trials to determine the optimum 
level of process parameters. The correlation of the dimensional accuracy with processing parameters of plastic injection moulding is a complicated issue. Thus, the objective of this study is to determine the optimum level of process parameters for improving the dimensional accuracy of Fresnel lens during plastic injection molding using Taguchi design method. The most significant factor that affects the microgroove depth of Fresnel lens was also investigated. Twenty test parts were employed to prove the effectiveness of Taguchi design method after the optimum level of process parameters were determined.

\section{EXPERIMENT}

Fig. 1 shows the schematic illustration of four master pattern models, which was designed by Pro/ENGINEER software. Fig. 2 shows the four master pattern models with given dimensions. The model was then exported to the FDM QuicksliceTM software via the stereolithography format. Fig. 3 shows the slicing results of four master pattern models using the CatalystEX slicing software. Table 1 shows the parameters for four master pattern models. Once the stereolithography file has been exported to QuicksliceTM, it was then horizontally sliced into many thin sections for fabricating the master pattern model, as shown in Fig. 4.

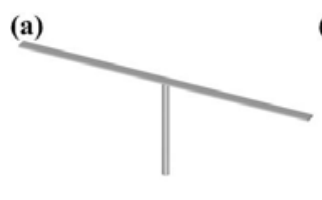

(c)

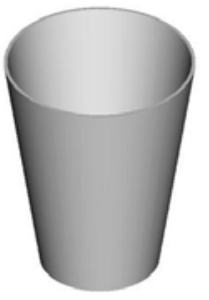

(b)

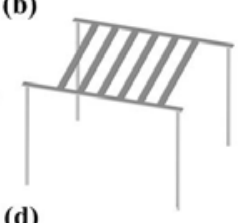

(d)

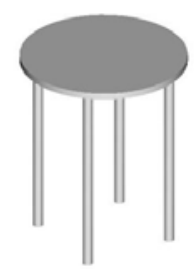

Fig. 1. Schematic illustration of four master pattern models

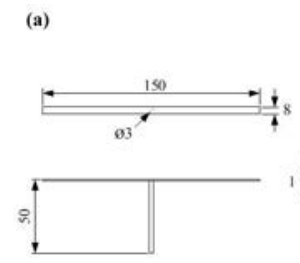

(c)

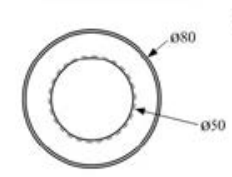

(d)
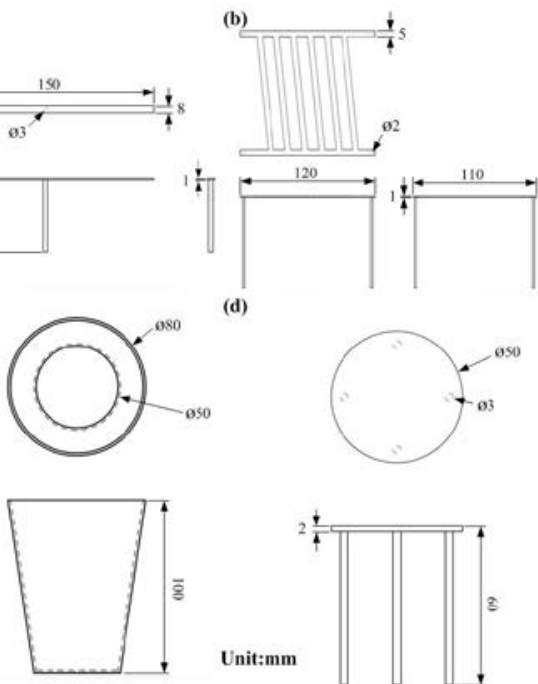

Fig. 2. Designed four master pattern models with given dimensions

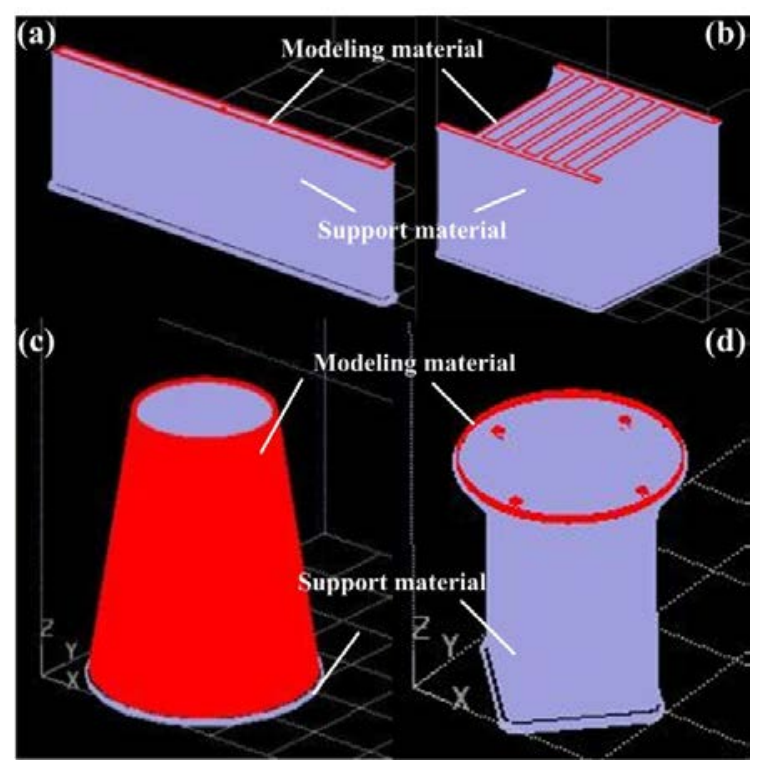

Fig. 3. Slicing results of four master pattern models using the CatalystEX slicing software

Table 1. Parameters for four master pattern models

\begin{tabular}{|c|c|c|c|}
\hline No. & $\begin{array}{c}\text { Layer thickness } \\
(\mathrm{mm})\end{array}$ & $\begin{array}{c}\text { Volume of } \\
\text { modeling } \\
\text { material }\left(\mathrm{cm}^{3}\right)\end{array}$ & $\begin{array}{c}\text { Volume of } \\
\text { support material } \\
\left(\mathrm{cm}^{3}\right)\end{array}$ \\
\hline \multirow{2}{*}{$\mathrm{a}$} & \multirow{3}{*}{0.254} & 1.37 & 60.01 \\
\hline b & & 6.15 & 132.52 \\
\cline { 1 - 2 } c & & 32.26 & 80.86 \\
\hline d & & 5.63 & 50.19 \\
\hline
\end{tabular}

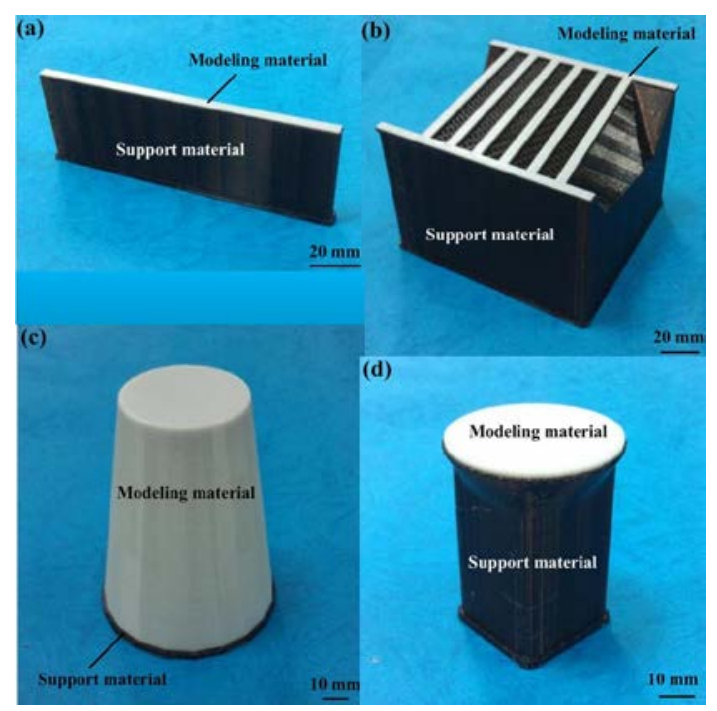

Fig. 4. Four master pattern models with the support structure. White part and black part shown in the figure indicate the modeling material and the support material, respectively

The fabricated material used in manufacturing the test parts was acrylonitrile butadiene styrene. Support materials were removed from RP part by ultrasonic machine (frequency $=46 \mathrm{kHz}$ ) when the object was fabricated. Alkaline compound $(\mathrm{NaOH})$ was used to make the solution for removing support material from RP part. Ceramic heater was used to heat the solution. The $\mathrm{pH}$ value meter ( $\mathrm{pH}$ value5011) was used to measure the variations of $\mathrm{pH}$ value during removing process. The $\mathrm{pH}$ value of solution was measured every one minute during removing process. 
A digital thermometer was used to measure the temperature of solution before removing process. In general, the $\mathrm{pH}$ value of the solvent change with temperature. The $\mathrm{pH}$ value was changed to 12 when the solution was heated from room temperature to $70^{\circ} \mathrm{C}$ [11]. Thus, the $\mathrm{pH} 12$ of solution was set as a starting point and the temperature of solution was fixed at $70^{\circ} \mathrm{C}$ during removing process. Effects of compensation point of $\mathrm{pH}$ value and times of compensation on the removal efficiency of support material were analyzed and discussed. Ten compensation points of $\mathrm{pH}$ value were employed to investigate the optimal compensation point. Three test parts were further employed to investigate the efficiency of removing support material from $\mathrm{RP}$ parts using $\mathrm{pH}$ value compensation technology.

\section{RESULTS AND DISCUSSION}

Fig. 5 shows the $\mathrm{pH}$ value as a function of the removing time without applying compensation technology. As can be seen, the entire removing time is 100 minutes. To shorten the removing time, $\mathrm{pH}$ value compensation technology was used. The weights of the solvent for ten compensation points are $11.88 \mathrm{~g}, 10.8 \mathrm{~g}, 9.72 \mathrm{~g}, 8.64 \mathrm{~g}$, $7.56 \mathrm{~g}, \quad 6.48 \mathrm{~g}, \quad 5.4 \mathrm{~g}, \quad 4.32 \mathrm{~g}, 3.24 \mathrm{~g}$, and $2.16 \mathrm{~g}$, respectively. The entire removing time is obviously reduced as compared with those without applying $\mathrm{pH}$ value compensation technology.

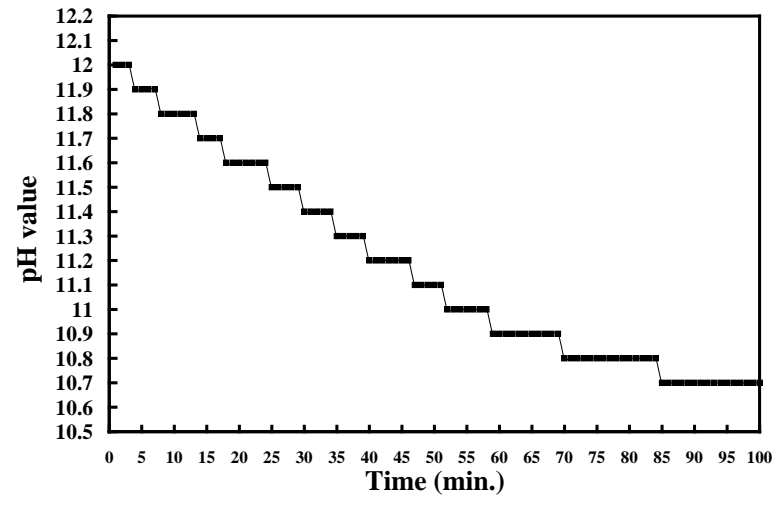

Fig. 5. The $\mathrm{pH}$ value as a function of the removing time without applying compensation technology

Fig. 6 shows the removing time as a function of ten compensation points. As it can be recognized from this figure, the $\mathrm{pH}$ value 11.6 is a good candidate for compensating the solution during removing process because the compensation points form $\mathrm{pH}$ value 11.6 to $\mathrm{pH}$ value 11.5 is too early and the compensation points form $\mathrm{pH}$ value 11.7 to $\mathrm{pH}$ value 11.8 is too late. For the compensation point of $\mathrm{pH}$ value 11.6, the entire removing time is reduced to only 38 minutes.

Fig. 7 shows the removing time as a function of the number of compensation time. Two phenomena were observed. One is the entire removing time decreases with increasing the times of compensation and the other is the entire removing time was significantly reduced. The entire removing time was significantly reduced to only 39 minutes by five times compensation, while the entire removing time was 137 minutes without applying $\mathrm{pH}$ value compensation technology. This means that the efficiency of removing support material increases with increasing the times of compensation. Fig. 8 shows the situation of removing process. To further evaluate the efficiency of removing process using the $\mathrm{pH}$ value compensation technology proposed, three test specimens was employed for investigation. Fig. 9 shows the removing time of three evaluation samples with and without applying $\mathrm{pH}$ value compensation technology.

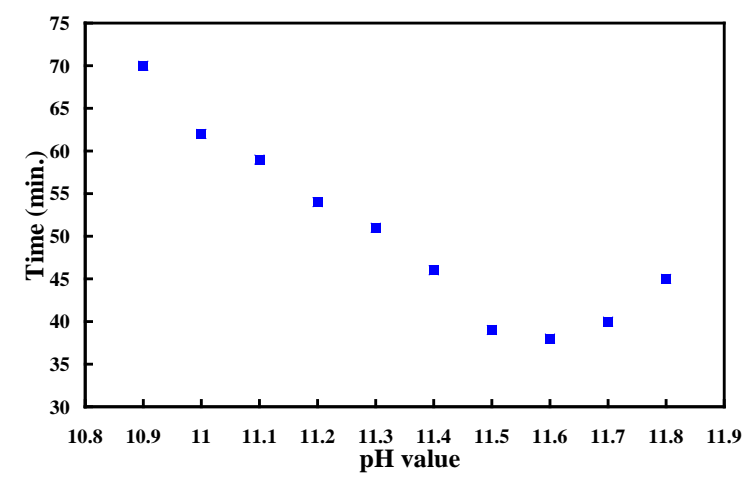

Fig. 6. Removing time as a function of ten compensation points

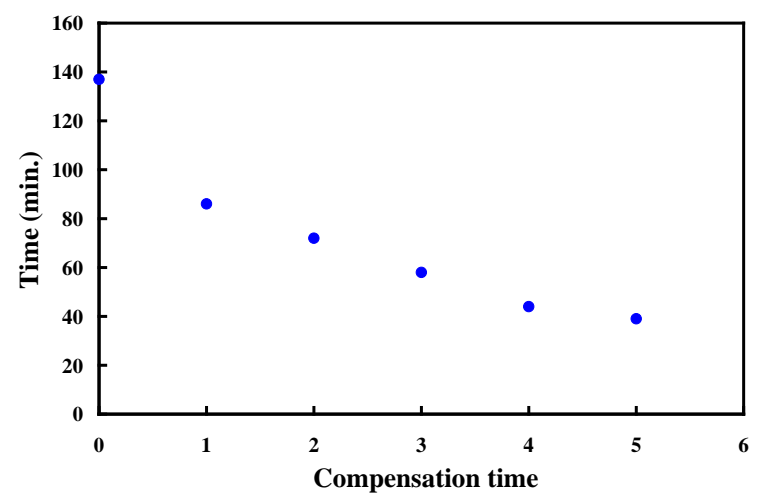

Fig. 7. Removing time as a function of the number of compensation time

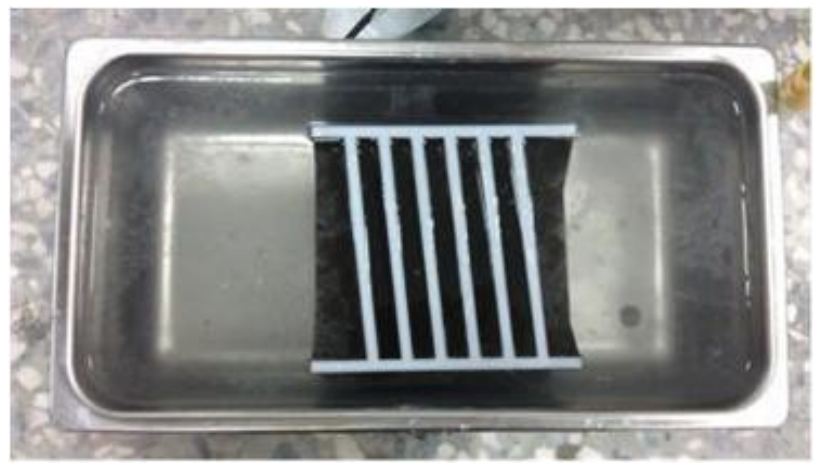

Fig. 8. Situation of removing process

As can be seen, the savings in the removing time for master pattern model a, b and c is $72 \%, 63 \%$ and $63 \%$, respectively. This means that the savings in the removing time is up to $72 \%$ using $\mathrm{pH}$ value compensation technology. Based on the results described above, compensation point and times of compensation are the two critical parameters in the removing process. But, the most important parameter affecting the efficiency of removing process is compensation point. Fig. 10 shows four RP parts after removing support materials. This technology has broad application prospects in the development of a new 
product using a FDM rapid prototyping system [12, 13] and rapid tooling technology [14]. Current results were performed manually. Further investigations focusing on the automation of $\mathrm{pH}$ monitoring with automatic compensation using microcontroller are in progress [15].

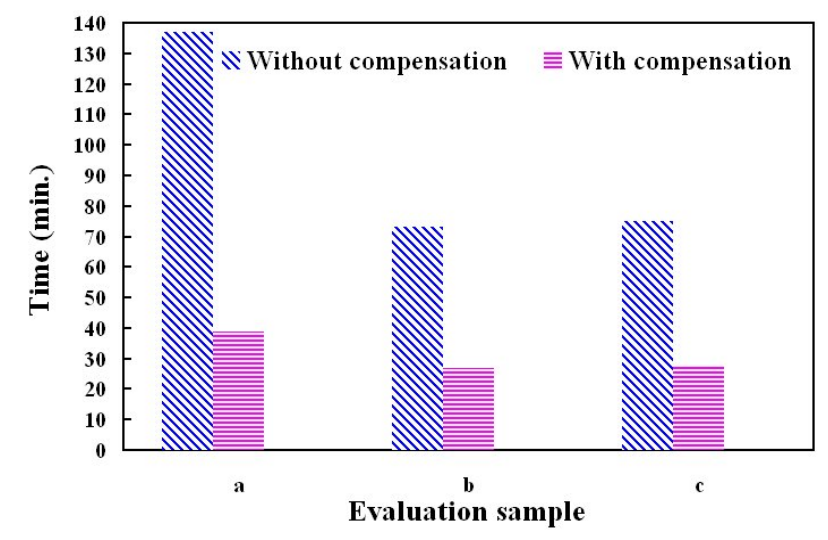

Fig. 9. Removing time of three evaluation samples with and without applying $\mathrm{pH}$ value compensation technology

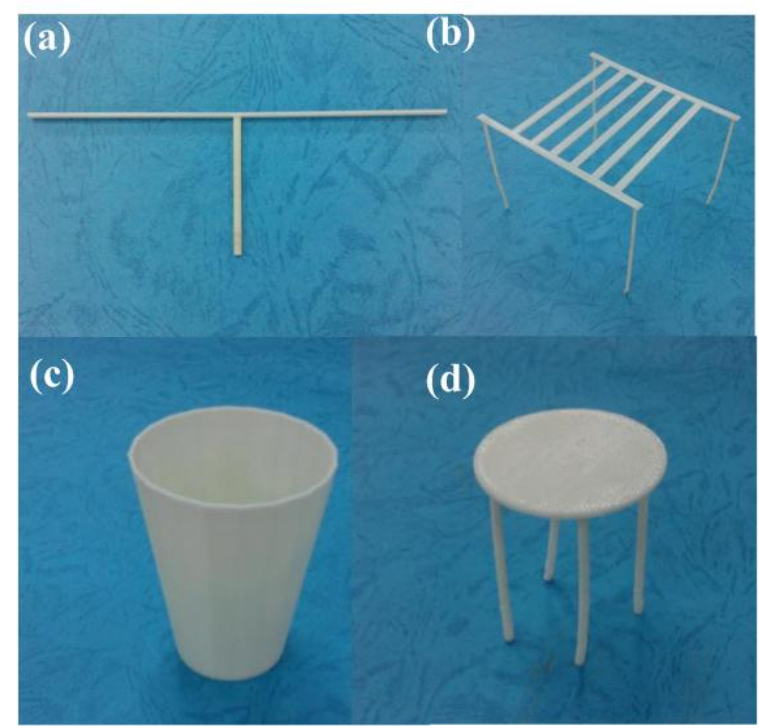

Fig. 10. Four RP parts after removing support materials

\section{CONCLUSIONS}

The target of RP is to reduce product development cost and lead times. A method for enhancing the efficiency of removing support material from $\mathrm{RP}$ parts using $\mathrm{pH}$ value compensation technology has been proposed in this work. The advantages of $\mathrm{pH}$ value compensation technology have been presented through test samples. The $\mathrm{pH}$ value 11.6 has been proved as a good candidate for compensating the solution during removing process. The efficiency of removing support material increases with increasing the times of compensation. The savings in the removing time up to $72 \%$ can be reached using $\mathrm{pH}$ value compensation technology.

\section{Acknowledgments}

The authors gratefully acknowledge the financial support of the Ministry of Science and Technology of Taiwan under contracts nos. NSC 102-2221-E-131-012 and NSC 101-2221-E-131-007.

\section{REFERENCES}

1. Es-Said, O. S., Foyos, J., Noorani, R., Mendelson, M., Marloth, R., Pregger, B. A. Effect of Layer Orientation on Mechanical Properties of Rapid Prototyped Samples Materials and Manufacturing Processes 15 2000: pp. $107-122$.

2. Laub, M., Jennissen, H. P., Seul, T., Schmachtenberg, E. Molecular Modelling of Bone Morphogenetic Protein-2 (BMP-2) by 3D-rapid Prototyping Materialwissenschaft und Werkstofftechnik 32 2001: pp. 926-930. http://dx.doi.org/10.1002/15214052(200112)32:12<926::AID-MAWE926>3.0.CO;2-1

3. Ahn, D., Kweon, J. H., Kwon, S., Song, J., Lee, S. Representation of Surface Roughness in Fused Deposition Modeling Journal of Materials Processing Technology 209 2009: pp. 5593-5600.

4. Yang, Y., Fuh, J. Y. H., Loh, H. T., Wong, Y. S. Multiorientational Deposition to Minimize Support in the Layered Manufacturing Process Journal of Manufacturing Systems 22 2003: pp. $116-129$.

5. Masood, S. H., Song, W. Q. Development of New Metal/polymer Materials for Rapid Tooling Using Fused Deposition Modelling Materials \& Design 252004 : pp. 587-594.

6. Choi, J. W., Medina, F., Kim, C., Espalin, D., Rodriguez, D., Stucker, B., Wicker, R. Development of a Mobile Fused Deposition Modeling System with Enhanced Manufacturing Flexibility Journal of Materials Processing Technology 211 2011: pp. 424-432.

7. Tellis, B. C., Szivek, J. A., Bliss, C. L., Margolis, D. S., Vaidyanathan, R. K., Calvert, P. Trabecular Scaffolds Created Using Micro CT Guided Fused Deposition Modeling Materials Science \& Engineering C Materials for Biological Applications 28 2008: pp. 171-178. http://dx.doi.org/10.1016/j.msec.2006.11.010

8. Gronet, P. M., Waskewic, G. A., Richardson, C. Preformed Acrylic Cranial Implants Using Fused Deposition Modeling: A Clinical Report The Journal of Prosthetic Dentistry 90 2003: pp. 429-433.

http://dx.doi.org/10.1016/j.prosdent.2003.08.023

9. Kuo, C. C., Tsou, Y. C., Chen, B. C. Enhancing the Efficiency of Removing Support Material from Rapid Prototype Parts Materialwissenschaft und Werkstofftechnik 43 2012: pp. 234-240.

10. Kuo, C. C., Tsou, Y. C. Effects of $\mathrm{pH}$ Value and Temperature of Solution on the Removal Efficiency of Support Material, Materialwissenschaft und Werkstofftechnik 43 2012: pp. 886-891. http://dx.doi.org/10.1002/mawe.201200964

11. Roses, M. Determination of the $\mathrm{pH}$ of Binary Mobile Phases for Reversed-phase Liquid Chromatography The Journal of Chromatography A 1037 2004: pp. 283-298.

12. Pandey, P. M., Thrimurthulu, K., Reddy, N. V. Optimal Part Deposition Orientation in FDM by Using a Multicriteria Genetic Algorithm International Journal of Production Research 42 2004: pp. 4069-4089.

13. Reddy, B. V., Reddy, N. V., Ghosh, A. Fused Deposition Modelling Using Direct Extrusion Virtual and Physical Prototyping 2 2007: pp. 51-60. http://dx.doi.org/10.1080/17452750701336486

14. Kuo, C. C. A Simple and Cost-effective Method for Fabricating Epoxy-based Composite Mold Inserts Materials and Manufacturing Processes 27 2012: pp. 383-388.

15. Sivanandam, S. N., Sumathi, S., Deepa, S. N. Design and Implementation of PLC Cum Micro-controller Based Electrically Synchronized Lift Indian Journal of Engineering and Materials Sciences 12 2005: pp. 269-277. 